\title{
DETERMINING STABILITY CONSTANTS OF NARINGENIN (4', 5, 7-TRIHYDROXY FLAVANONE) COMPLEXES WITH ALUMINIUM (III) AND IRON (II) BY POTENTIOMETRIC AND SPECTROPHOTOMETRIC METHODS
}

Recep Karadag ' , Gulbin Erdogan ${ }^{2}$,, Mehmet Bayar ${ }^{3}$, Emre Dolen ${ }^{2}$

'Laboratory for Natural Dyes, Faculty of Fine Arts, Marmara

University, 81018 Acıbadem, ,Kadikoy, Istanbul, Turkey

${ }^{2}$ Department of Analytical Chemistry, Faculty of Pharmacy, Marmara

University, 34660, Haydarpasa, Istanbul, Turkey

${ }^{3}$ Department of Analytical Chemistry, Faculty of Arts and Sciences, Marmara University, 81040, Kadikoy, Istanbul, Turkey

\begin{abstract}
Naringenin and its metal complexes are used extensively in chemistry, biology and dye industry. In this study, complexes of naringenin with aluminium and iron are examined by spectrophotometric and potentiometric methods. The stability constants of these complexes were determined potentiometrically by using Calvin-Bjerrum and Irving Rossotti methods. The evaluated protonation constants of the naringenin were found: $\log \mathrm{K}_{1}=$ $10.19, \log K_{2}=8.31$, and $\log K_{3}=7.06$ at the $25^{\circ} \mathrm{C}$. Logarithms of the stability constants were found: for Aluminium complex : $\log \mathrm{K}_{1}=15.39 \log \mathrm{K}_{2}$ $=7.12$, and $\log \mathrm{K}_{3}=6.47$ and for Iron complex $: \log \mathrm{K}_{1}=10.11, \log \mathrm{K}_{2}=6.40$, and $\log \mathrm{K}_{3}=6.11$ at the $25^{\circ} \mathrm{C}$. The components of metal-naringenin complexes are given 1:3 (metal: naringenin ratio) both $\mathrm{Al}(\mathrm{III})$ and $\mathrm{Fe}$ (II) from the results.
\end{abstract}

Key words: naringenin, iron, aluminium, stability constant, potentiometry, spectrophotometry

• Correspondence:gulbiner@yahoo.com 


\section{INTRODUCTION}

Flavonoids comprise a large group of naturally existing polyphenolic compounds containing over 4000 different chemical structures /1/ widely distributed throughout the plant kingdom. These are found in fruits, vegetables, nuts and seeds as well as most types of tea and red wine $/ 2 /$. These compounds are recognized by the presence of a $\mathrm{C}_{6}-\mathrm{C}_{3}-\mathrm{C}_{6}$ basic ring skeleton. Flavonoids differ from one another in the orientation of the substituents (hydroxyl and/or methyl etc.), the degree of unsaturation, the type of sugar moiety attached and the position of the benzenoid substitution /3/. Basic flavan nucleus;

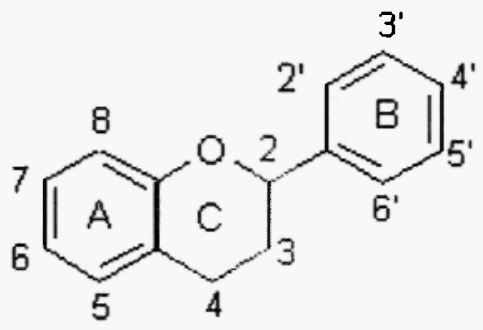

The major classes are flavones, isoflavones, flavans, anthocyanins, proanthcyanidins, flavanones, chalcones, and aurones $/ 4 /$.

Diverse biochemical properties of flavonoids have provoked interest in biology, biochemistry, food chemistry, dye industry, medicinal chemistry, and cosmetics. These compounds have exhibited a broad range of biological and pharmacological activities such as antioxidant, anti-allergic, antibacterial, anti-inflammatory, antimutagenic, anticancer, and anti-atherogenic effects $15,6 /$.

They usually contain one or more aromatic hydroxyl groups and this moiety is responsible for the antioxidant activity of the flavonoid. Due to their chemical composition, the flavonoid aglycons span the whole range from fully water- to fully lipid-soluble, allowing them to perform their antioxidative mode of action both in water solutions and in biological membranes $/ 1 /$.

Flavonoids are known to exhibit various biological effects such as inhibiting platcict aggregation, scavenging free radicals, preventing cell proliferation and reducing levels of low-density lipoproteins in plasma. In addition, these compounds are reported to modulate vascular tone. Several 
epidemiological studies revealed the inverse association between flavonoid intake and reduction in occurrence of cardiovascular diseases, such as myocardial infarction $/ 3,7 /$.

Flavonoids are the most important pharmacologically active constituents in propolis. Flavonoids are thought to account for much of the biologic activity in propolis. Among the most potent microbicidal compounds in propolis are flavonone pinocembrin (5,7-dihydroxyflavanone) and its 3-OH analogue flavonol galangin (3,5,7-trihydroxyflavon)/8/.

Flavonoids are main individual chemical components of natural dye extracts, and have been used as natural dyes since ancient times. Flavonoids in natural dyes in extracts from wool and silk fibres from archeological textiles are determined. The examined objects originate from 4th to 12th Century Egypt and belong to the collection of Early Christian Art of the National Museum in Warsaw 19\%. Natural dyes are reported as potent antimicrobial agents owing to the presence of a large amount of tannins. Several other sources of plant dyes are reported to exhibit antibacterial and antifungal activity $/ 10,11 /$.

One of the main groups of flavonoids that occur as glycosides are flavanones. Flavanones were exclusively analyzed in citrus fruits (oranges and grapefruits) since these compounds are concentrated in this plant family and are not likely to be found in others. Naringenin was related to a large number of beneficial effects such as cancer chemopreventive agents, mutagenic inhibitor, genotoxicity inhibitor, as an agent to lower plasma cholesterol with hypocholesterolemic properties, an antioxidant agent and has blood lipid-lowering activity. One likely explanation for these effects is that dietary plants contain substances able to control basic cellular processes such as the endogenous defense against oxidative stress e.g. by means of the regulation of the glutation levels and cytochromes P450 /12/.

More recently, the protective effect of naringenin against ethanol-induced gastric lesions in rats is reported. Epidemiological studies indicate a protective relationship between the consumption of citrus fruits or juices and the risk of ischaemic stroke and lung cancer. Most flavanones are found as glycosides (bound to sugar). The antioxidant activity of naringenin could also be ascribed to its phenolic acid metabolites in rats namely phydroxyphenylpropioinc acid, $p$-coumaric acid and $p$-hydroxybenzoic acid. In conclusion, naringenin, a natural occurring flavonoid, attenuates the nephrotoxicity of cisplatin in rats $/ 2 \%$. 
Naringenin are found the most in Everlostings or strawllowers (varieties of Helichrysum). Naringenin, a glycon of naringin, was found to inhibit the formation of aortic atherosclerotic lesions in rabbits fed a high cholesterol diet. In addition, previous studies showed that naringenin and its derivative exhibited hypocholesterolemic activities by reducing cholesterol biosynthesis and cholesterol esterification in high cholesterol-fed rats $/ 5,13 /$.

It is resistant for washing and abrasion with lightfastness, so it is used as a natural yellow dye extract in dye industry /14/.

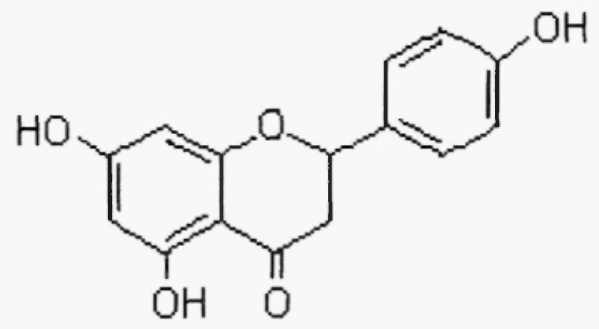

\section{Chemical structure of naringenin (4', 5, 7-trihydroxy flavanone)}

The protonation constants of naringenin and stability constants of naringenin-metal complexes are determined. The stability constants of complexes have been calculated potentiometrically using Calvin-Bjerrum and Irving-Rossotti methods $/ 15 /$.

Because of the insolubility of naringenin in water, dioxane-water mixture $(1: 1 . v / v)$ was used in all workings. Behaviour of $\mathrm{H}^{+}$ion in the water-dioxane $(1 / 1: v / v)$ mixture is the same as aqueous solutions $/ 16,17,18,19 /$.

\section{EXPERIMENTAL}

\section{Instrumentation}

For spectrophotometric studies Shimadzu-UV-1600PC UV-VIS doublebeam spectrophotometer was used. For potentiometric studies, Radiometer TIM800 Titration Manager, ABU 901 Autoburette and HI 1131B Combination $\mathrm{pH}$ electrode were used. Computer calculations were performed on the $\mathrm{pH}$-metric data. 


\section{Chemicals and Reagents}

$\mathrm{HClO}_{4}(\% 70-72,1,67 \mathrm{~g} / \mathrm{mL}), \mathrm{NaClO}_{4}, 1,4$-dioxane, $\mathrm{Al}\left(\mathrm{NO}_{3}\right)_{3} .9 \mathrm{H}_{2} \mathrm{O}$ were obtained from Merck, $\mathrm{Fe}\left(\mathrm{NH}_{4}\right)_{2}\left(\mathrm{SO}_{4}\right)_{2} \cdot 6 \mathrm{H}_{2} \mathrm{O}$ was purchased from Carlo Erba. Naringenin (4', 5, 7-trihydroxy flavanone) was provided from Carl Roth Gmbh. All reagents were of highest commercial quality. A solution of $0,01 \mathrm{~N} \mathrm{NaOH}$ was prepared from "Titrisol Merck". The concentration of $\mathrm{Fe}$ (II) and $\mathrm{Al}$ (III) ions in the solution was typically kept at $4.10^{-3} \mathrm{molL}-1$ and determined accurately by titrating it with standart ethylenediamine tetraacetic acid (EDTA). A solution of $0.1 \mathrm{~N}$ EDTA was prepared from "Titrisol Merck". The purity and the concentrations of the prepared solution were checked by potentiometric titration method. The ionic strength of the reaction medium was kept constant at $25^{\circ} \mathrm{C}(\mathrm{l}=0.0045)$ using $\mathrm{NaClO}_{4}$ solution.

\section{METHODS}

\section{Potentiometric Studies}

\section{The determination of Protonation and Stability Constants}

In order to determine the protonation constants the solutions including $\mathrm{HClO}_{4}$ and ligand (naringenin) $+\mathrm{HClO}_{4}$ were titrated potentiometrically using $0.010 \mathrm{molL}^{-1} \mathrm{NaOH}$ (Fig.1). Average $\overline{\mathrm{n}}_{\mathrm{A}}$ values were calculated from the titration curves.

For the calculation, the following equation are given below:

$$
\bar{n}_{A}=y+\frac{\left(V_{1}-V_{2}\right)(N+C)}{\left(V_{0}+V_{1}\right) C_{L}}
$$

The protonation constant of the naringenin and the stability constant of naringenin-metal complexes which were used as ligand were determined in Table 1.

The stability constant of the binary complexes were determined potentiometrically using the Irwing-Rossotti method /15/. Therefore the mixture which the metal ions were titrated with standard $0.010 \mathrm{molL}^{-1} \mathrm{NaOH}$ solution potentiometrically and the titration curves were plotted (Fig.l). $\bar{n}_{1}$ values were calculated using $\bar{n}_{A}$ values and the equation given below; $\mathrm{pL}$ 
values were calculated using $\bar{n}_{1}$. values to calculate stability constants. The following equation was used to calculate $\bar{n}_{\mathrm{L}}$ values:

$$
-n_{L}=\frac{\left(V_{3}-V_{2}\right)\left[N+C+C_{L}\left(y-\bar{n}_{A}\right)\right]}{\left(V_{0}+V_{2}\right) \cdot \bar{n}_{A} \cdot C_{M}}
$$

Where:

$\mathrm{V}_{\mathrm{v}}=$ Initial volume $(\mathrm{mL})$

$\mathrm{N}=$ Molarity of the base $(\mathrm{NaOH})$

$: 25.00 \mathrm{~mL}$

$\mathrm{C}_{\mathrm{M}}=$ Metal concentration

$: 0.01000 \mathrm{molL}^{-1}$

$\mathrm{C}_{\mathrm{I}}=$ Naringenin $(\mathrm{L})$ concentration

: $0.00040 \mathrm{molL}^{-1}$

$\mathrm{C}=\mathrm{HClO}_{4}$ concentration

$: 0.00040 \mathrm{molL}^{-1}$

$y=$ Number of protons given for naringenin $: 1$

$\mathrm{V}_{1}, \mathrm{~V}, \mathrm{~V}_{3}=\mathrm{NaOH}$ volumes of $\mathrm{V}_{1}, \mathrm{~V}_{2}$ and $\mathrm{V}_{3}$ were read from the titration curves which contain $\mathrm{HClO}_{4}$, ligand $+\mathrm{HClO}_{4}$ and $\mathrm{HClO}_{4}+\mathrm{Ligand}+$ Metal ions.

$\bar{n}_{\Lambda}=\bar{n}_{\Lambda}$ values which correspond to different $\mathrm{pH}$ values were calculated by using the volumes of $\mathrm{V}_{1}$ and $\mathrm{V}_{2}$ and were plotted in function of $\mathrm{pH}$, i.e. $\overline{\mathrm{n}}_{\mathrm{A}}=\mathrm{f}(\mathrm{pH})$.

The following equation was used to calculate $\mathrm{pL}$ values:

$$
\frac{1+\beta_{1}\left[H^{+}\right]+\beta_{2}\left[H^{+}\right]^{2}+\ldots \beta_{n}\left[H^{+}\right]^{n}}{C_{1}-\bar{n}_{L} \cdot C_{M}}
$$

$\bar{n}_{1}=$ The values were calculated using $\bar{n}_{\Lambda}$ values and the equation (b)

$\mathrm{pL}=\mathrm{pL}$ values were calculated using $\beta$ values $(\beta$ values were calculated as follows).

The relation $\bar{n}_{\mathrm{L}}=\mathrm{f}(\mathrm{pL})$ was plotted using $\bar{n}_{\mathrm{L}}$ and $\mathrm{pL}$ values which were calculated for each metal ion. The stability constants were determined from these graphs (Fig. 3, 6 and Table 1).

The formation constant $(\beta)$ were determined from stability constant metal-ligand complexes/20/.

For naringenin-Al(Ill) complex

$$
\left(\log K_{1}=15.39\right) \quad \beta_{1}=2,45.10^{11}
$$




$$
\begin{array}{ll}
\left(\log \mathrm{K}_{2}=7.12\right) & \beta_{2}=3,23 \cdot 10^{18} \\
\left(\log \mathrm{K}_{3}=6.47\right) & \beta_{3}=2,34 \cdot 10^{36}
\end{array}
$$

For naringenin-Fe(II) complex

$$
\begin{array}{ll}
\left(\log K_{1}=10.11\right) & \beta_{1}=1,29.10^{10} \\
\left(\log K_{2}=6.40\right) & \beta_{2}=3,24 \cdot 10^{16} \\
\left(\log K_{3}=6.11\right) & \beta_{3}=2,55 \cdot 10^{27}
\end{array}
$$

The following equation was used to calculate the conditional formation constant $(\operatorname{logK})$ for $\mathrm{pH} 0$ to 14 :

$$
\begin{array}{ll}
\log \mathrm{K}=\log \mathrm{K}_{1.2 .3}{ }^{\mathrm{M}} * \alpha_{\mathrm{M}^{*}} & {\left[\left(\log \mathrm{K}_{1}{ }^{\mathrm{L}} * \log \mathrm{K}_{2}{ }^{\mathrm{L}} * \log \mathrm{K}_{3}{ }^{\mathrm{L}}\right) /\left[\left(\mathrm{H}^{+}\right)^{3}+\mathrm{K}_{1}{ }^{\mathrm{L}} *\left(\mathrm{H}^{+}\right)^{2}+\right.\right.} \\
\left.\left.\mathrm{K}_{1}{ }^{\mathrm{L}} * \mathrm{~K}_{2}{ }^{\mathrm{L}}\left(\mathrm{H}^{+}\right)+\mathrm{K}_{1}{ }^{\mathrm{L}} * \mathrm{~K}_{2}{ }^{\mathrm{L}} * \mathrm{~K}_{3}{ }^{\mathrm{L}}\right]\right] & \\
\log _{1,2.3}{ }^{1} & =\text { Stability constants of ligand(naringenin) } \\
\log _{1.2 .3}{ }^{\mathrm{M}} & =\text { Formation constant of metal - ligand complex } \\
\mathrm{H}^{+} & =\text {The values at various } \mathrm{pH} 0 \text { to } 14
\end{array}
$$

$\alpha_{M}=$ The fraction of $\alpha_{M}$ of the metal ion in the uncomplexed form metal may be calculated $/ 20 /$.

\section{Sample Preparation}

The following solutions were prepared:

1) $0.001 \mathrm{molL}^{-1} \mathrm{HClO}_{4}$ and $0.01 \mathrm{molL}^{-1} \mathrm{NaClO}_{4}$ are dissolved in $25.0 \mathrm{~mL}$ dioxane- $\mathrm{H}_{2} \mathrm{O}$ mixture and mixed with $25.0 \mathrm{~mL}$ dioxane- $\mathrm{H}_{2} \mathrm{O}$ mixture.

2) $0.001 \mathrm{molL}^{-1} \mathrm{HClO}_{4}, 0.01 \mathrm{molL}^{-1} \mathrm{NaClO}_{4}$ and $0.004 \mathrm{molL}^{-1}$ naringenin are dissolved in $25.0 \mathrm{~mL}$ dioxane- $\mathrm{H}_{2} \mathrm{O}$ mixture and mixed $25.0 \mathrm{~mL}$ dioxane- $\mathrm{H}_{2} \mathrm{O}$ mixture.

3) $0.001 \mathrm{molL}^{-1} \mathrm{HClO}_{4}, 0.01 \mathrm{molL}^{-1} \mathrm{NaClO}_{4}$ and $0.004 \mathrm{molL}^{-1}$ naringenin are dissolved in $25.0 \mathrm{~mL}$ dioxane- $\mathrm{H}_{2} \mathrm{O}$. Then it is mixed with $0.006 \mathrm{~mol}$ $\mathrm{L}^{-1} \mathrm{Al}(\mathrm{III})$ in $25 \mathrm{~mL}$ dioxane $-\mathrm{H}_{2} \mathrm{O}$ mixture.

4) $0.001 \mathrm{molL}^{-1} \mathrm{HClO}_{4}, 0.01 \mathrm{molL}^{-1} \mathrm{NaClO}_{4}$ and $0.004 \mathrm{molL}^{-1}$ naringenin are dissolved in $25.0 \mathrm{~mL}$ dioxane- $\mathrm{H}_{2} \mathrm{O}$ mixture. Then it is mixed with 0.004 molL ${ }^{-1} \mathrm{Fe}(\mathrm{II})$ in $25 \mathrm{~mL}$ dioxane- $\mathrm{H}_{2} \mathrm{O}$ mixture.

Each mixture was separately titrated potentiometrically with $0.010 \mathrm{~mol} \mathrm{~L}$

${ }^{\prime} \mathrm{NaOH}$ (Fig. 1). The separation among $\left(\mathrm{HClO}_{4}\right),\left(\mathrm{HClO}_{4}+\mathrm{L}\right)$ and $\left(\mathrm{HClO}_{4}\right.$ $+\mathrm{L}+$ Metal) plots in all potentiometric titration curves showed the formation 
ol a metal-ligand complex.

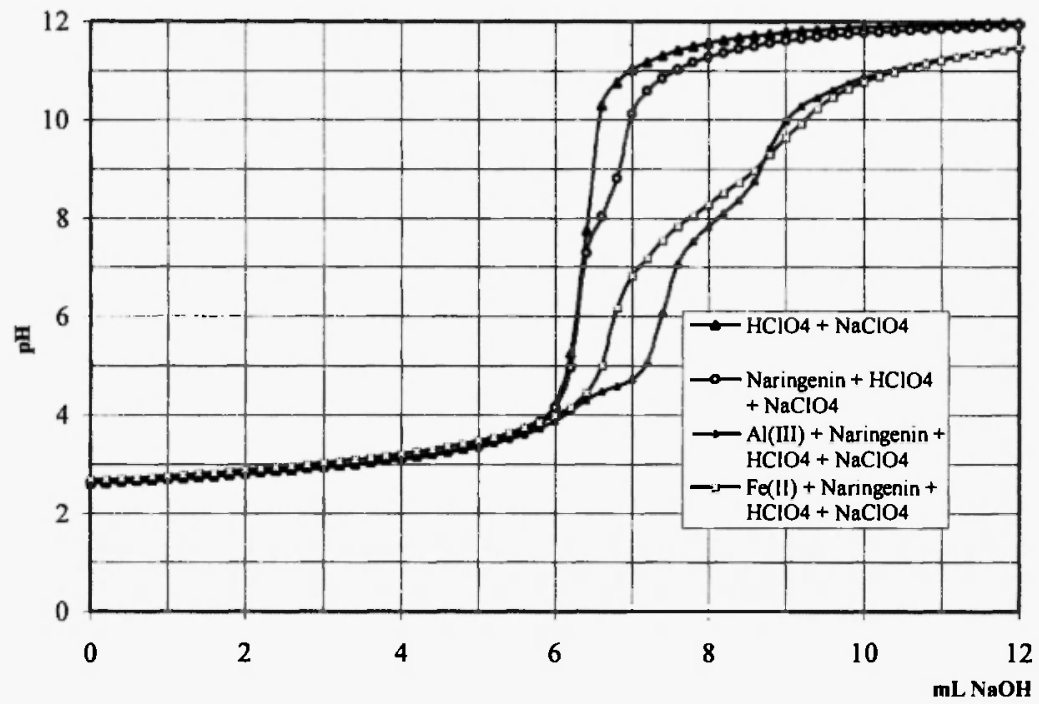

Fig. 1: Potentiometric titration curves.

For the titration of $\mathrm{HClO}_{4}+\mathrm{NaClO}_{4}$ with mixture of $\mathrm{HClO}_{4}+\mathrm{NaClO}_{4}+$ naringenin, $\overline{\mathrm{n}} \mathrm{A}=\mathrm{f}(\mathrm{pH})$ dependence was prepared. ( $\overline{\mathrm{n}} \mathrm{A}$ was calculated according to equation (a)). Then these protonation constants were found: $\log \mathrm{K}_{1}=10.19, \log \mathrm{K}_{2}=8.31$, and $\log \mathrm{K}_{3}=7.06$ at $25^{\circ} \mathrm{C}$ (Fig. 2).

To obtain the $\overline{\mathrm{n}} \mathrm{L}=\mathrm{f}(\mathrm{pL})$ dependence for the potentiometric titrations with $\mathrm{HClO}_{4}+\mathrm{NaClO}_{4}+$ naringenin $+[\mathrm{Al}(\mathrm{III})$ or $\mathrm{Fe}(\mathrm{II})]$ mixtures, equation (b) and cquation (c) were applied. (Figs. 3, 6 ).

By using calculated formation constants, the relative abundances of different species of metal-ligand complexes were found and were plotted as a function of $\mathrm{pH}$ (Fig.4, 7).

Furthermore, by using equation (d), the conditional formation constants were calculated and were plotted as a function of $\mathrm{pH}$ (Fig.5, 8). 
and E. Dolen

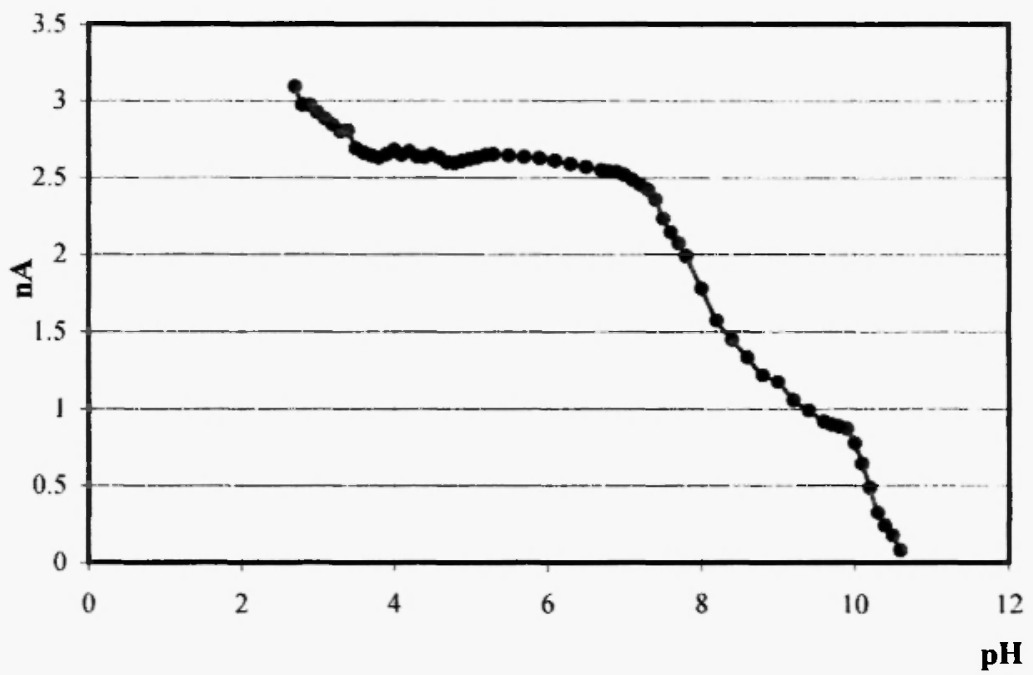

Fig. 2. $\bar{n} A=f(p H)$ curves for naringenin.

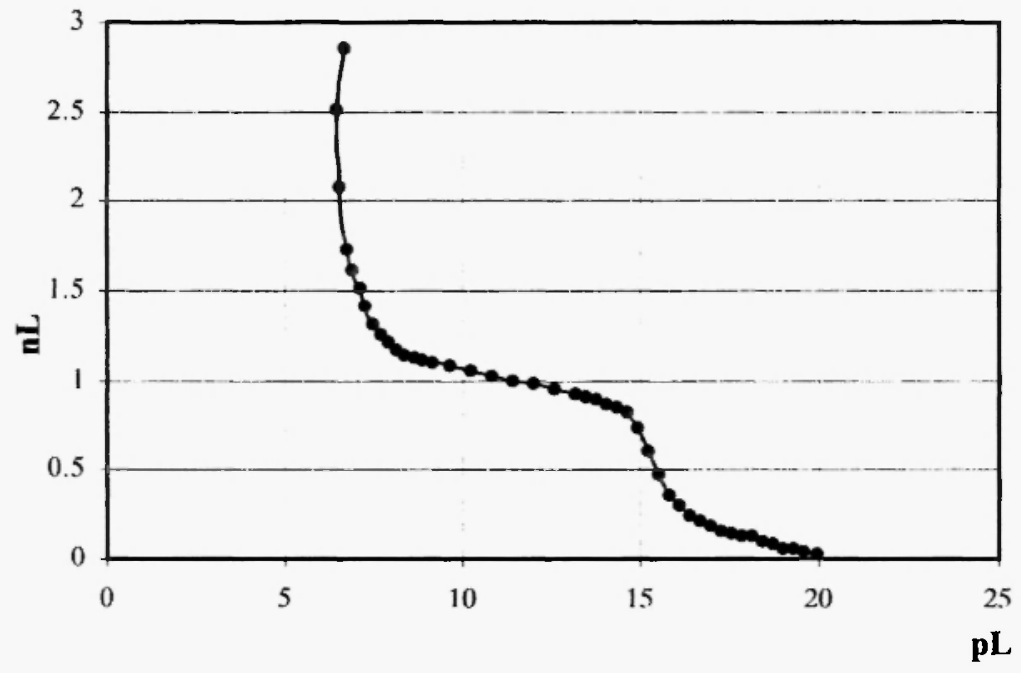

Fig. 3: $\bar{n} L=f(p L)$ curves for the $A l$ (III)-naringenin complex. 


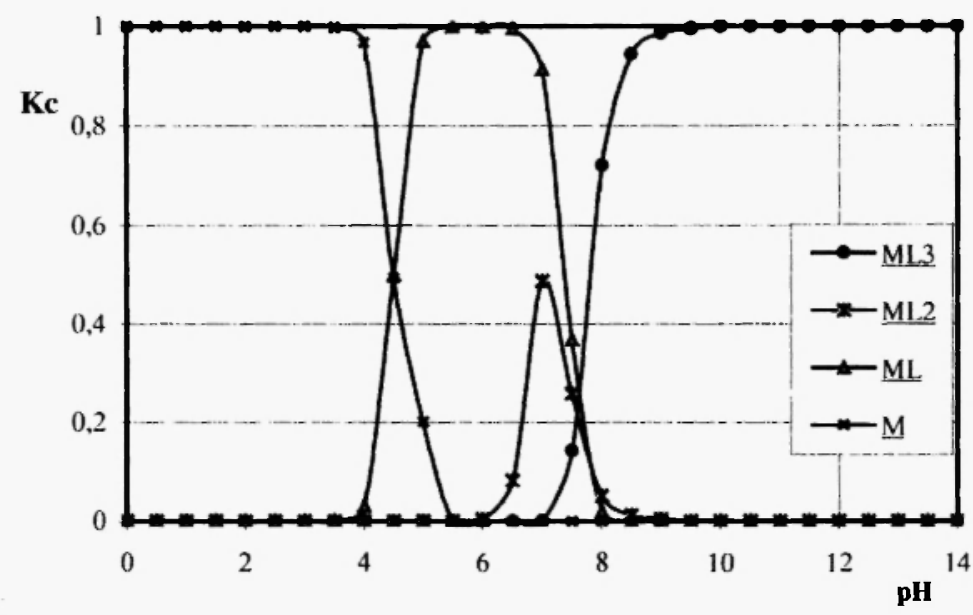

Fig. 4: Relative abundance of ionic and molecular species calculated as a function of $\mathrm{pH}$ for $\mathrm{Al}(\mathrm{III})$ - naringenin complex.

$\mathrm{M}+\mathrm{L} \rightarrow \mathrm{ML}$

$\mathrm{ML}+\mathrm{L} \rightarrow \mathrm{ML}_{2}$

$\mathrm{ML}_{2}+\mathrm{L} \rightarrow \mathrm{ML}_{3}$

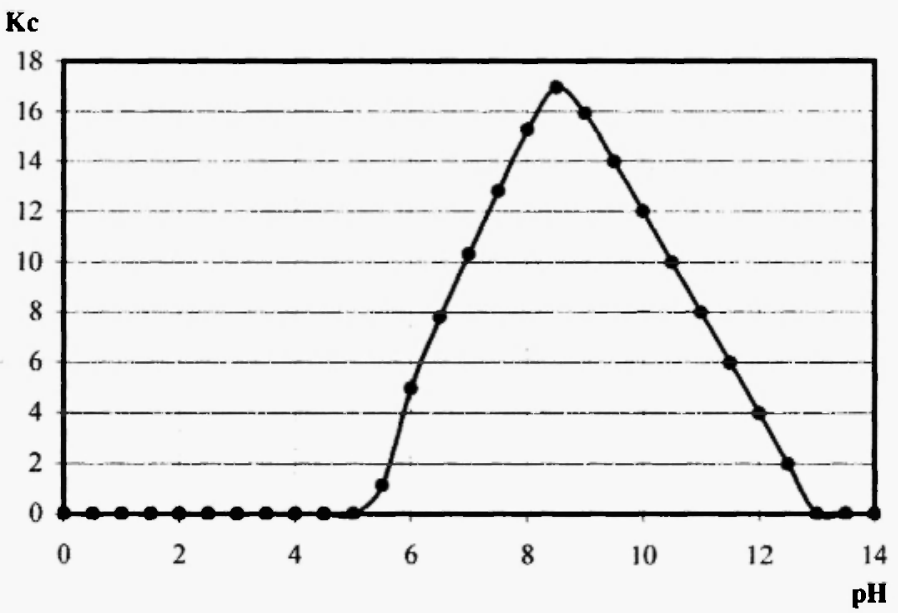

Fig. 5: Conditional formation constant as a function of $\mathrm{pH}$ for $\mathrm{Al}(\mathrm{III})$ naringenin complex. 


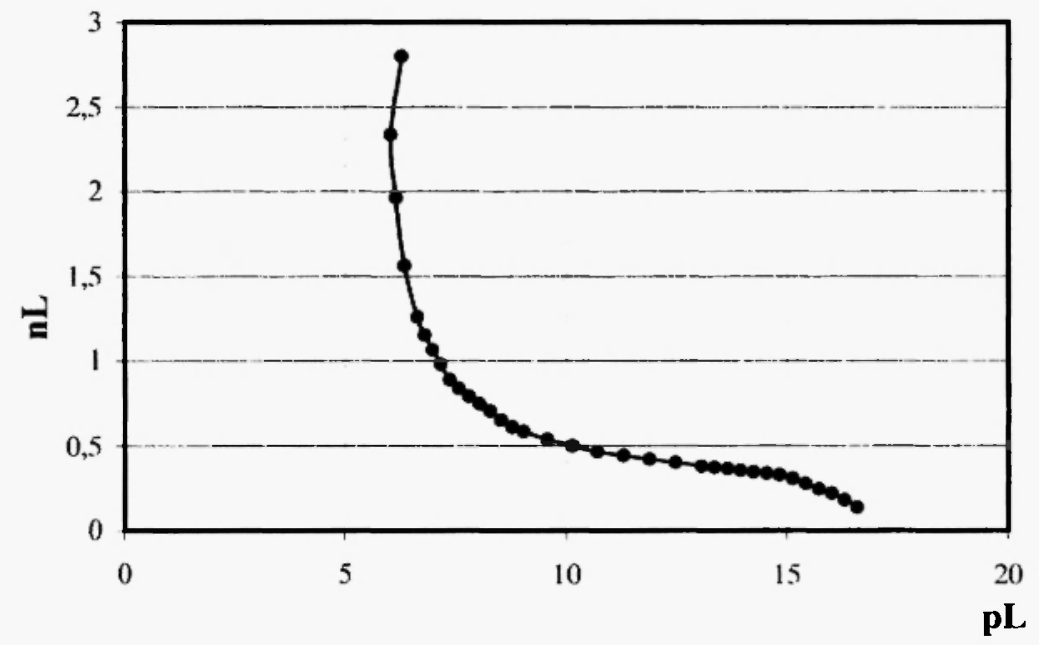

Fig. 6: $n L=f(p L)$ curves for the Fe(II)-naringenin complex.

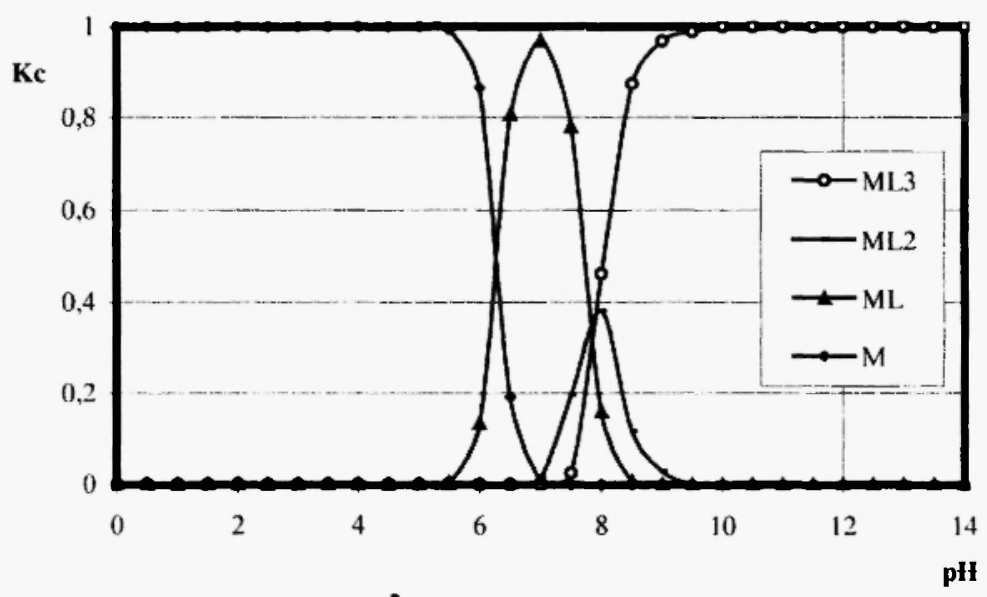

Fig. 7: Relative abundance of ionic and molecular species calculated as a function of $\mathrm{pH}$ for $\mathrm{Fe}(\mathrm{II})$ - naringenin complex.

$\mathrm{M}+\mathrm{L} \rightarrow \mathrm{ML}$

$\mathrm{ML}+\mathrm{L} \rightarrow \mathrm{ML}_{2}$

$\mathrm{ML}_{2}+\mathrm{L} \rightarrow \mathrm{ML}_{3}$ 


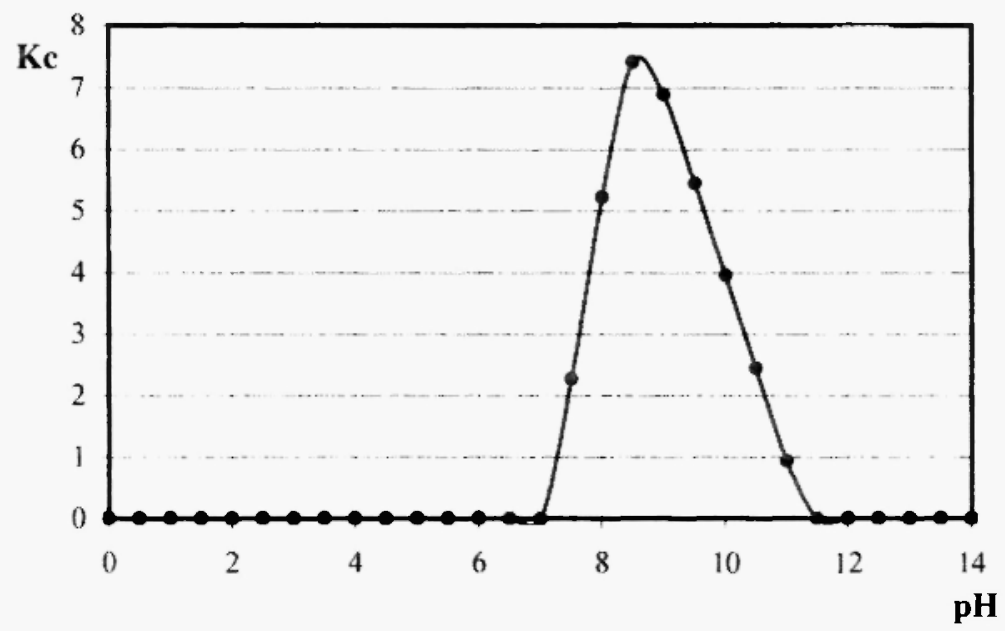

Fig. 8: Conditional formation constant as a function of $\mathrm{pH}$ for $\mathrm{Fe}(\mathrm{Il})$ naringenin complex.

\section{Spectrophotometric Studies}

In spectrophotometric measurements, $\mathrm{HClO}_{4}+\mathrm{NaClO}_{4}+$ dioxane $+\mathrm{H}_{2} \mathrm{O}$ mixture is used as reference, because the same composition is used for the potentiometric titration. Then, naringenin, aluminium(III) and iron(II) solutions are added separately to the reference mixture and absorption spectra are recorded lor each (Figs. 9, 10). A similar procedure for metal ions was performed separately in the absence of naringenin (Figs. 9 and 10 ). 


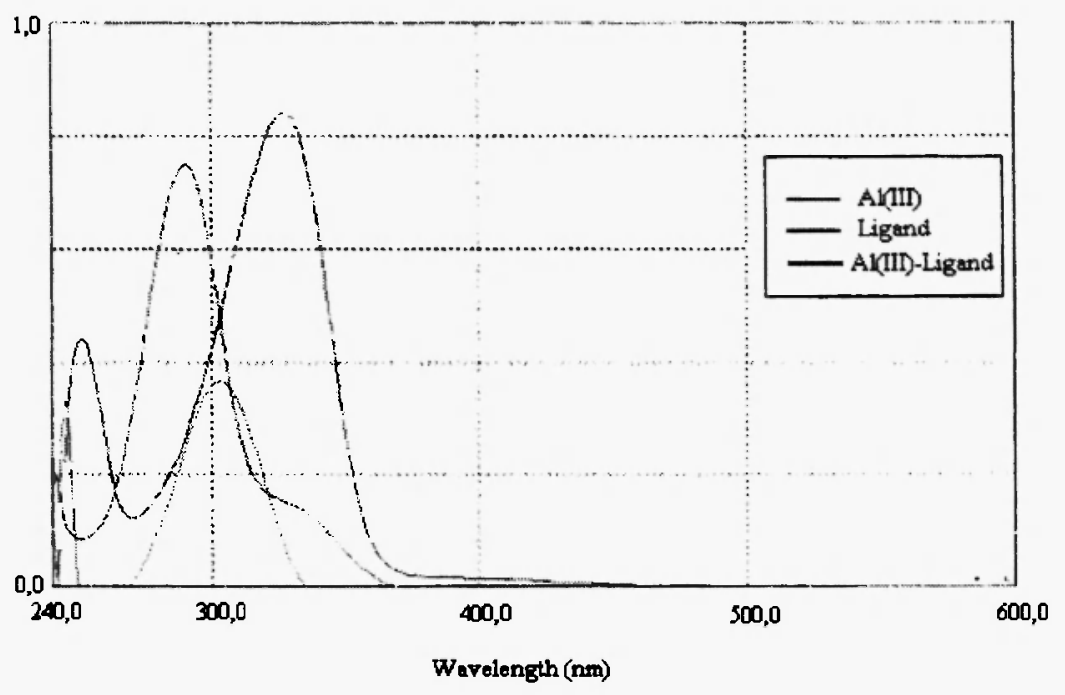

Fig. 9: UV-vis spectra of $\mathrm{Al}(\mathrm{III})$ ions, naringenin and $\mathrm{Al}(\mathrm{III})$-naringenin complex in 1:3 dioxane $+\mathrm{H}_{2} \mathrm{O}+\mathrm{HClO}_{4}+\mathrm{NaClO}_{4}(50 \mu \mathrm{M}$ at pH 8.50).

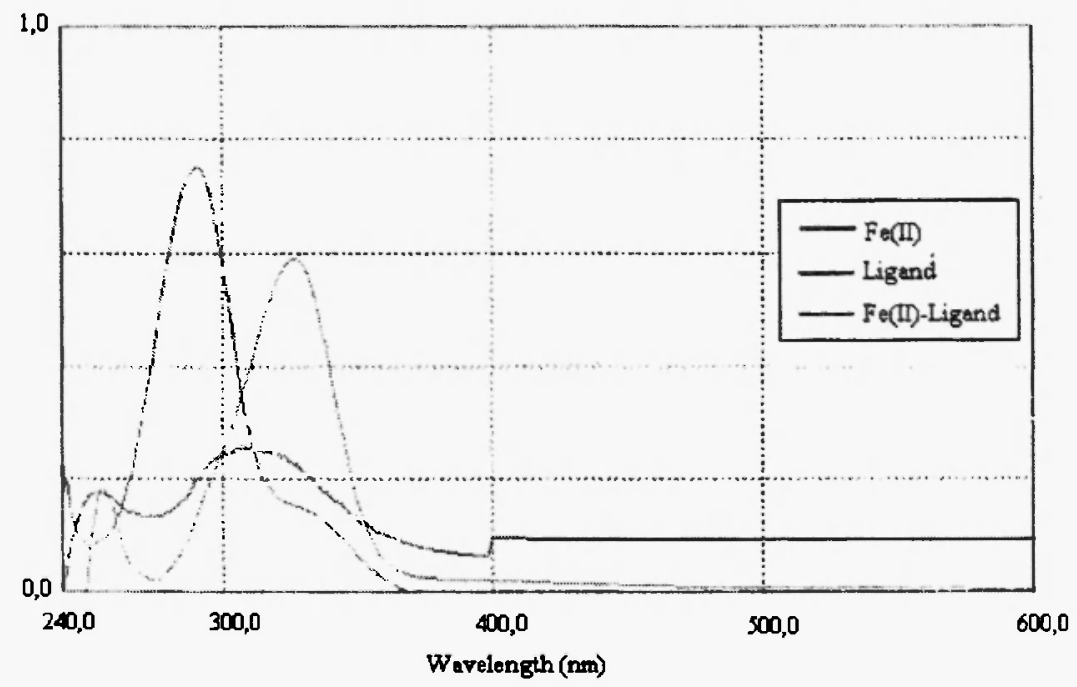

Fig. 10: UV-vis spectra of $\mathrm{Fe}$ (II) ions, naringenin and $\mathrm{Fe}$ (II)-naringenin complex in 1:3 dioxane $+\mathrm{H}_{2} \mathrm{O}+\mathrm{HClO}_{4}+\mathrm{NaClO}_{4}(50 \mu \mathrm{M}$ at $\mathrm{pH}$ 8.50). 


\section{RESULTS AND DISCUSSION}

Some of the metal salts, i.e. the aluminium(III) and iron(11) salts, which were used as mordant in traditional dyeing process with natural dyes, consist of flavonoids. In this study, the protonation constants of naringenin were determined potentiometrically by the Irwing-Rosotti method. The conditional formation constants were calculated and these constants were found to be in agreement with the formation constants of binary systems. In this calculation, $\mathrm{pK}$ values of ligand and the formation constants of complexes that they formed with metals were used as data. The formation constants of complexes were found from the formation curves $\bar{n} L=f(p L)$ which were drawn for aluminium(III) and iron(II) complexes. The conditional formation constants equal the " $\beta$ values" of the complex. The formation constants of metalnaringenin complexes found in this study are in agreement with the calculated conditional formation constants of $\beta$. The conditional formation constants, namely the stability constants of complexes, can also be calculated. The behaviour of aluminium(III) and iron(II) ions has been examined in this work.

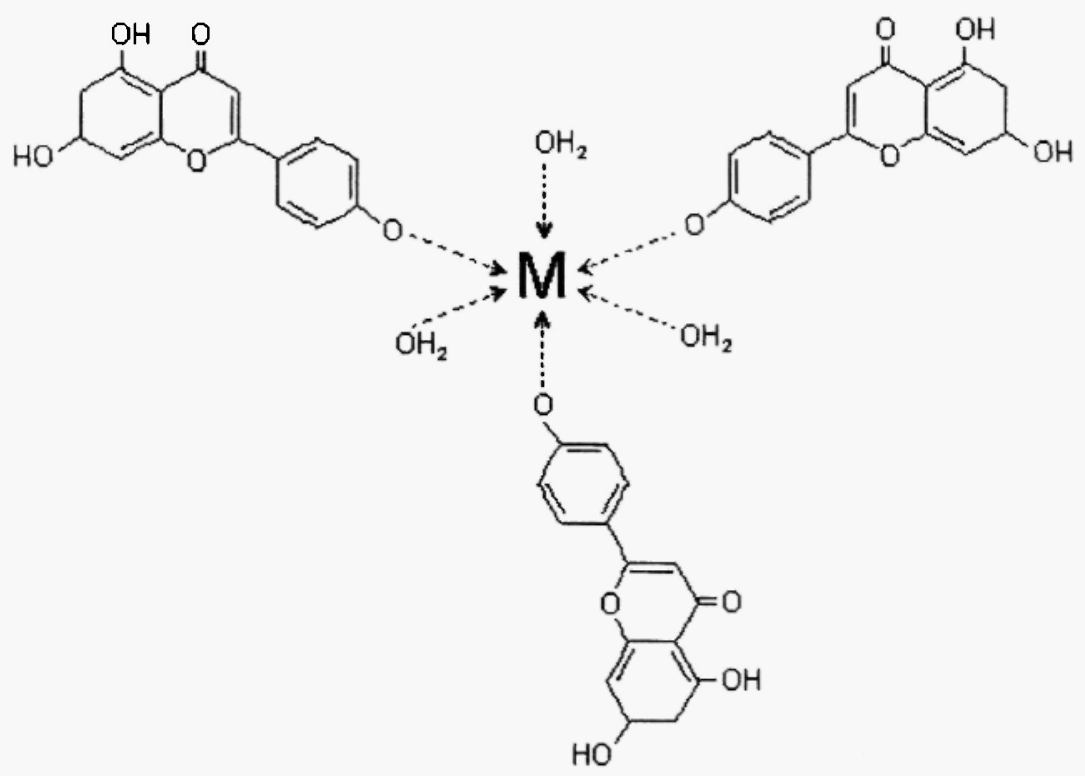

Fig. 11: Proposed structure of naringenin-metal complexes: (M $=\mathrm{Al}(\mathrm{III})$ or $\mathrm{Fe}(\mathrm{II})$ ions). 
From the experiment results, we can conclude that naringenin-metal complexes 3:1 (naringenin:metal ratio) both $\mathrm{Al}(\mathrm{III})$ and $\mathrm{Fe}(\mathrm{II})$. Since coordination number for both iron and aluminium is 6 , that complex contains 3 water molecules $/ 18,19 /$. The proposed structure of naringenin-metal complexes is given in Figure 11. The protonation constant of the naringenin and the stability constant of naringenin-metal complexes were determined in Table 1.

Table 1

The stability constants for $\mathrm{Al}(\mathrm{III})$-naringenin and $\mathrm{Fe}(\mathrm{II})$-naringenin complexes

\begin{tabular}{lccc}
\hline & $\log K_{1}$ & $\log K_{2}$ & $\log K_{3}$ \\
\hline Naringenin & 10,19 & 8,31 & 7,06 \\
Al(III)-Naringenin & 15,39 & 7,12 & 6,47 \\
Fe(II)-Naringenin & 10,11 & 6,40 & 6,11 \\
\hline
\end{tabular}

The conditional formation constant for $\mathrm{Al}(\mathrm{III})$-naringenin complex was found as the maximum value 16,94 at the range of $\mathrm{pH}=8-9$ (Fig. 5). This value is in accordance with the relative abundance (Fig. 4). The conditional formation constant for $\mathrm{Fe}(\mathrm{II})$-naringenin complex was found as the maximum value 7,41 at the range of $\mathrm{pH}=7-11,5$ (Fig. 8). This value is in accordance with the relative abundance (Fig. 7). The complex formation shows a maximum in a narrow $\mathrm{pH}$ range and by decreasing with the increase of $\mathrm{pH}$. (Fig 5,8).

Table 2

Maximum absorption wavelengths.

\begin{tabular}{ll} 
Naringenin & 290,50 \\
$\mathrm{Al}(\mathrm{III})$ & 303,00 \\
$\mathrm{Al}(\mathrm{III})-$ Naringenin & 327,00 \\
$\mathrm{Fe}(\mathrm{II})$ & 310,50 \\
$\mathrm{Fe}(\mathrm{II})$-Naringenin & 326,50 \\
\hline
\end{tabular}

According to the spectra in Figure 9, $\mathrm{Al}(\mathrm{III})$ ions, naringenin and $\mathrm{Al}(\mathrm{III})-$ naringenin complex exhibit maxima at the wavelength of $303.00,290.50$, and 
$327.00 \mathrm{~nm}$ respectively (Table II). At $290.50 \mathrm{~nm}$ and $303.00 \mathrm{~nm}$ absorption of $\mathrm{Al}(\mathrm{III})$ ions and naringenin decrease, while absorption of the $\mathrm{Al}$ (III)naringenin is increased at $327.00 \mathrm{~nm}$. After the reaction was completed, no absorption signal originating either from $\mathrm{AI}(\mathrm{III})$ or naringenin was observed. Similar conclusions could be drawn from the spectrum of Fe(II)-naringenin complex. Although $\mathrm{Fe}(\mathrm{II})$ ions absorb at $310.50 \mathrm{~nm}$, the iron(II)-naringenin complex absorbes at $326.50 \mathrm{~nm}$ (Table II). Therefore, with the progress of the complexation, absorption signals of naringenin and $\mathrm{Fe}(\mathrm{II})$ ions decreased. while absorption of Fe(II)-naringenin complex was enhanced (Fig. 10). After the reaction was completed, one could observe only the latter.

The results presented are in good agreement with the previous ones for naringenin (258 $\mathrm{nm} ; 373 \mathrm{~nm})$ obtained by Markham $/ 21 \%$.

\section{REFERENCES}

1. C. V. Dijk, A. J. M. Driessen and K. Recourt, Biochem. Pharmacology, 1593-1600 (2000).

2. O. A. Badary, S. Abdel-Maksoud, W. A. Ahmed and G. H. Owieda, Life Sciences, 76-8, 2125-2135 (2005).

3. M. Ajay, A. H. Gilani and M. R. Mustafa, Life Sciences, 74-5, 603-612 (2003).

4. R. J. Hughes, T. R. Croley, C. D. Metcalfe and R. E. March, International Journal of Mass Spectrometry, 371-385 (2001).

5. S. Lee, C. Lee, S. Moon, E. Kim, C. Kim, B. Kim, S. and T. Jeong, Bioorganic \& Medicinal Chemistry Letters, 2003, 3901-3903.

6. P. Hodek, P. Trefil and M. Stiborova, Chemico-Biological Interactions, 139-1, 1-21 (2002).

7. M.T. Fernandez, M.L. Mira, M.H. Florencio, and K.J. Jennings, Journal of Inorganic Biochemistry, 92-2, 105-111 (2002).

8. U. Ataç, K. Sorkun, O. Oncag, D. Coğulu. O. Gencay, and B. Salih, Microbiological Research, 160-2, 189-195 (2005).

9. J. Orska-Gawry, I. Surowiec, J. Kehl, H. Rejniak, K.Urbaniak-Walczak and M. Trojanowicz, Journal of Chromatography, 989-2, 239-248 (2003).

10. R.K. Sarkar and P.D. Chauhan, Man Made Textiles India, 2001, 460467. 
11. R. Singh, A. Jain, S. Panwar, D. Gupta and S.K. Khare, Dyes and Pigments, 66-2, 99-102 (2005).

12. A.A. Franke, J. C. Lauric, C. Arakaki and P.S. Murphy, Juurnal of Food Composition and Analysis, 17-1, 1-35 (2004).

13. K.F.R. Santos, T.T. Oliveira, T.J. Nagem, A.S. Pinto and M.G.A. Oliveira, Pharmacological Research, 40-6, 493-496 (1999).

14. R. Karadag, and H. Böhmer, "Dyes in History and Archaelogy", 16, 106 (2001).

15. H. M. Irwing and H.S. Rossotti, J. Chem. Soc., 1953, 3397-3405, 1954, 2904-2910.

16. G.F.Van Uitert, and C. Fernelius, J. Am. Chem. Soc., 75, 3682 (1953).

17. R. Karadag, Chem. Anal.(Warsaw), 48, 931 (2003).

18. G. Erdogan and R. Karadag, Reviews in Analytical Chemistry, 24-1, 923 (2005).

19. G. Erdogan, R. Karadag and E. Dolen, Reviews in Analytical Chemistry, 24-4, 247-26I (2005).

20. H.A. Laitinen and W.E. Harris, Chemical Analysis, Second Edition, 130-194 (1975).

21. K. R. Markham, Techniques of Flavonoid Identification, Academic Press London (1982). 
